\title{
The Impact of Education on Third Births. A Multilevel Discrete-Time Hazard Analysis
}

\author{
Marc Callens \\ Christophe Croux
}

\begin{abstract}
We propose to use multilevel discrete-time hazard models to assess the impact of societal and individual level covariates on the timing and occurrence of third births. We focus mainly on the impact of educational attainment on third births across 15 European countries. From the analysis in this paper, the effect of education on the propensity to have a third child is found to be negative. This education effect is not significantly weakened by the Nordic countries, but living in Scandanavia does increase the hazard for a third birth.
\end{abstract}

Keywords: Multilevel Analysis, Discrete-Time Hazard Analysis, Multilevel Hazard Analysis, Life Course Events.

\footnotetext{
* Dept. of Applied Economics, Katholieke Universiteit Leuven, Naamsestraat 69, B-3000 Leuven, Belgium, Email: Marc.Callens@econ.kuleuven.ac.be, Christophe.Croux@econ.kuleuven.ac.be
} 


\section{Introduction}

The aim of this paper is to empirically assess whether and how the impact of the mother's educational level on the timing and the occurrence of third births varies across Europe.

From a theoretical point of view, it is quite generally accepted that education has a negative effect on the propensity to have children (Kasarda et al., 1986). A core explanation for this comes from economic theory: a higher income may well increase the demand for children but the higher opportunity cost of having another child is assumed to outperform this income effect. It is also assumed that higher educated women have a more efficient use of contraception. In some recent country-specific empirical research, however, no or even a (slightly) positive relationship between the educational level of mothers and third birth rates was observed (Sweden: Hoem \& Hoem, 1989 and Berinde, 1999; Norway: Kravdal, 1992; Belgium: Callens, 1997 and Austria: Hoem et al., 1999). In other countries (France: Corman, 2000) the negative relationship still prevails.

How can we bridge the gap between conventional theory and apparently counterintuitive effects found in recent country-specific studies? The relationship between education and fertility may vary because of country-level factors such as the social welfare system, the relative economic position of the highly educated women, the use of contraception, the value system, ...causing heterogeneity among countries.

The data for this study are individual level-data for 15 European countries, stemming from the Fertility and Family Survey (FFS) standardised database (United Nations Economic Commission for Europe, Geneva). Use is made of multilevel discrete-time hazard analysis to model the impact that both individual and country level covariates (Nordic vs. other European countries) may have on the propensity to have a third child. In particular, we focus on education as an individual covariate and as a country level covariate on "Nordic vs other European countries". Combining elements from several statistical areas, it becomes possible to formulate such a hierarchical model in terms of a generalised linear mixed model for Bernoulli response variables.

From the analysis in this paper, we conclude that classical economic theory is not falsified. The effect of education on the propensity to have a third child is found to be 
negative and is not significantly weakened by the Nordic countries. But, living in Scandinavia compared to other European countries does increase the hazard for a third birth.

\section{Data}

\subsection{Working Sample}

Our analysis is based on data from the international Fertility and Family Surveyproject (FFS) of the Economic Commission for Europe of the United Nations (ECE, Geneva, 1988-1999). In this database on reproductive behaviour retrospective individual-level data are brought together from 24 developed countries.

In our study, we actually have only 14 FFS datasets at our disposal: Austria ( $\mathrm{n}=$ 6120), Belgium $(n=5433)$, Germany $(n=10012)$, Finland $(n=5825)$, France $(n=$ 4885), Hungary $(n=5487)$, Italy $(n=6030)$, Latvia $(n=4200)$, Lithuania $(n=5000)$, Norway $(n=5562)$, Poland $(n=8546)$, Slovenia $(n=4559)$, Spain $(n=6013)$ and Sweden $(n=4984)$. As the survey in Germany was held in 1992, most of the retrospective data refers to the period before the unification. For this reason, we have split up the data set for Germany into two countries: Germany-East $(n=5036)$ and Germany-West $(n=4976)$. So, in our analysis we pretend to have 15 countries.

We restrict the working sample to mothers with at least two births within the same first marital or non-marital union, which we call a birth-union after Hoem et al. (1999). So, women who never lived in a union or have at most one child are not in the working sample. We also exclude mothers that live in a recently formed union where children from previous unions are present. We further exclude women with twins at first and/or second births and women with a first inter-birth interval exceeding 7 years. Also, women pregnant with a third child at the date of the interview are excluded from the analysis. Finally, some records with missing, suspicious or impossible dates are deleted (e.g., descending birth dates).

All the above selection criteria result in a working sample of 17.222 women of which 5.409 had a third birth (i.e., a selection rate of 0.314). In Table 1, we present for this working sample the sample size, the fieldwork period and the range for the year of 
birth of the mother by country. The fieldwork period and birth cohort vary considerably among FFS-country samples, but the statistical analysis controls for this heterogeneity. To compensate for disproportionate sampling of females, we use weight factors for every individual.

(Table 1, about here)

\subsection{Dependent Variable}

The quantity of interest is the probability that a two-child mother gives birth to a third child during a specific month, given that a third birth has not already occurred to that mother before. Essentially we analyse the time length from the second to the third birth measured in monthly units, which we call the period at risk. The start of the period at risk is chosen to be ten months past the birth date of the second child. The period of risk ends at the birth of a third child or at a censoring event: the divorce from the current partner or the interview, whichever comes first. We also censor the period of risk at nine years since the second birth or at the age of 40 , if this applies. This censoring is accounted for by the estimation method.

\subsection{Covariates}

A popular way to explain fertility differentials is the proximate determinants framework. In this framework, there are only four direct effects: marriage, breast feeding, induced abortion and contraception. Socio-economic and cultural factors act trough intermediary factors such as contraception use, abortion and extra-marital birth (Bongaarts and Potter, 1983).

However, in this study socio-economic factors are specified to have a direct effect on fertility differentials. We try to capture the impact of these factors on two levels: the individual level and the country-level. At the individual level, we use female educational attainment as a determinant of fertility. At the societal level we make a distinction between the Scandinavian countries and other European countries. Variables of particular theoretical interest are education of the mother and the distinction between Scandinavian and other European countries. 
We use education (Educ) as a proxy for human capital effects on fertility. We have collapsed the original International Standard Classification of Education coding system for educational level into three categories low, medium and high. Typically, country-differentials are explored in an analysis with a limited number of countries (typically two to four), which are known to be different on some theoretical relevant dimensions. Another analysis approach is to cluster countries according to some geographical criterion such as north south or east west and to select one country per cluster for separate analysis. In this study, we have chosen to make a distinction between the Nordic countries and other European countries (Scandinavia). The Nordic societies (Sweden, Norway and Finland) have many characteristics in relation to the family building process, family values and gender equality in common that make them rather distinct from other countries in Europe.

We also include three controlling variables in this study: ever worked more than three months, year of birth of the mother and duration of the first birth interval. To control for the possible confounding effect of female labour force participation with education, we are using the binary variable ever worked more than three months (Labour). Next, to catch the changes in behaviour across generations, we have also added the variable year of birth of the mother (Cohort) in the analysis. Due to the retrospective nature of the FFS survey, selection bias may arise because the "at least two-child" mothers at the moment of the interview may not be representative for the "at least two-child" mothers in general. Typically the selection is biased towards women who married early and had two children relatively quickly. Such women will tend to be more fertile but less educated than the average women. Following Hobcraft and Rodriguez (1992), we use a measure of exposure and/or past reproductive behaviour to control for possible selection bias: duration of the first birth interval (Interbirth) measured in months.

Finally, Time (i.e. time since the second birth) will be introduced in the regression model as just another explanatory covariate. 


\section{Method of Analysis}

\subsection{Discrete-Time Hazard Analysis}

Births can occur at any point in time. Thus, for the analysis of birth histories it is appropriate to use continuous-time models such as the Cox model. However, data about birth histories are typically collected via retrospective surveys. In such surveys it is common practice to record dates in large grouped-time intervals such as months or years. Application of continuous-time models to grouped-time survival data is not recommended because of the problem of the large number of ties (i.e., more than one individual experiences an event at the same time).

To overcome difficulties that continuous-time methods have with these grouped-time data, alternative methods have been developed (Allison, 1982). A popular alternative is the discrete-time approach, where time is treated as tough it were truly discrete (Myers, Hankey and Mantel, 1973; Brown, 1975).

In the discrete-time approach survival time (i.e., time until an event) is considered as a discrete random variable $T_{i}$ which can take on positive integers values only. We observe $T_{i}$ for $n$ independent individuals, and we denote their realisations by $t_{i}$ for $1 \leq$ $i \leq n$. At time $t$ either the event occurs or the observation is censored. Censoring means that the individual is not observed beyond $t$. The censoring process is described by an indicator variable $\delta_{i}$, which is set to 1 if an individual $i$ is uncensored and which is set to zero otherwise. As usual, we assume that the censoring process is non-informative. For each individual $i$, we have also a vector of covariates $\boldsymbol{x}_{i t}$, which may be time-varying.

The discrete-time hazard rate $p_{i t}$ is defined as the conditional probability that a person $i$ experiences an event at discrete-time $t$, given the event has not already occurred to that individual before $t$ :

$$
p_{i t}=\operatorname{Pr}\left(T_{i}=t \mid T_{i} \geq t\right)
$$

This conditional probability is called the discrete-time hazard rate, or the risk of experiencing an event at discrete-time $t$. This conditional probability plays a major role in the analysis of event histories. It is a measure for expressing the chance of an individual of experiencing an event as that individual survives over time. 
A very popular specification for the dependence of the hazard rate on time $t$ and a set of explanatory variables $\boldsymbol{x}$ is provided by the logistic regression function:

$$
p_{i t}=1 /\left[1+\exp \left(-\left(\alpha_{t}+\beta^{\prime} x_{i t}\right)\right)\right]
$$

We can rewrite this in the logit, or log-odds form as:

$$
\operatorname{logit}\left(p_{i t}\right)=\log \left[p_{i t} /\left(1-p_{i t}\right)\right]=\alpha_{t}+\beta^{\prime} x_{i t}
$$

In this specification $\alpha_{t}$ is a set of constants, one for each discrete-time point, and is called the baseline hazard. As a parametric specification of the baseline hazard $\alpha_{t}$ we selected a quadratic function of time. This yields the variables Time and Timesq as additional covariates. This analysis strategy only uses two extra degrees of freedom and it has been shown that misspecification is minimal (Adams and Watson, 1989).

Discrete-time hazard models can be estimated via conventional maximum likelihood estimation. The total likelihood of the data is given by:

$$
L=\prod_{i=1}^{n}\left[\operatorname{Pr}\left(T_{i}=t_{i}\right)\right]^{\delta_{i}}\left[\operatorname{Pr}\left(T_{i}>t_{i}\right)\right]^{1-\delta_{i}}
$$

By taking the log, we get the log-likelihood function, which can be rewritten and expressed as (See Allison, 1982):

$$
\log L=\sum_{i=1}^{n} \delta_{i} \log \left\{p_{i t_{i}} /\left(1-p_{i t_{i}}\right)\right\}+\sum_{i=1}^{n} \sum_{j=1}^{t_{i}} \log \left(1-p_{i j}\right)
$$

If we introduce a dummy variable $y_{i t}$ equal to 1 if an individual experiences an event at time $t$ and equal to zero if not, we then can rewrite the log-likelihood in (3b) as:

$$
\log L=\sum_{i=1}^{n} \sum_{j=1}^{t_{i}} y_{i t} \log \left\{p_{i j} /\left(1-p_{i j}\right)\right\}+\sum_{i=1}^{n} \sum_{j=1}^{t_{i}} \log \left(1-p_{i j}\right)
$$

which is simply the log-likelihood for the regression analysis of binary data. This means that discrete-time hazard rate models can be estimated by using programs for the analysis of binary data, as shown in Brown (1975). So in practice we treat each discrete-time unit for each individual as a separate observation. For each separate observation, the response variable is coded one if an event has taken place at that particular discrete-time unit, and zero otherwise.

\subsection{Hierarchical Discrete-Time Hazard Analysis}

We regard the FFS-data as hierarchically nested with individuals at the lower level and countries at the higher level. In such a multilevel system, we can identify three 
classes of propositions: (1) propositions about micro relations (2) propositions about macro relations and (3) propositions about macro-micro relations. In macro-micro relations both micro- and macro level variables are dealt with.

Several extensions of single level regression models have been suggested to deal with hierarchically nested propositions. Kreft and de Leeuw (1998) notice three different approaches: (1) traditional non-hierarchical extensions (e.g. separate regressions), (2) classical contextual models (e.g. analysis of covariance) and (3) modern multilevel models (random components). In this study we will apply all three methods: separate regressions and analysis of covariance regression are used in the exploratory part of the study and random components to confirm the results.

In separate regressions, 15 models are estimated separately, one for each country $j$, which gives in the case of discrete-time hazard analysis:

$$
\operatorname{logit}\left(p_{i t j}\right)=\log \left\lfloor p_{i t j} /\left(1-p_{i t j}\right)\right\rfloor=\alpha_{j}+\beta_{j}{ }^{\prime} x_{i t j}
$$

for $i=1, \ldots, n_{j}$ and $t=1, \ldots, t_{i}$, where $n_{j}$ is the number of mothers in the study belonging to country $j$. From a statistical point of view, a main problem with this approach is the lack of parsimony, especially when the number of groups at the higher level is large. Statistical power can be gained by pooling the data from the different countries.

In analysis of covariance (ANCOVA) both the individual level and the context level are present. Individual-level explanatory variables have the same role as in ordinary regression, but the groups are entered as (J-1) dummy variables to code group membership; again for the discrete-time hazard analysis model:

$$
\operatorname{logit}\left(p_{i t j}\right)=\log \left\lfloor p_{i t j} /\left(1-p_{i t j}\right)\right\rfloor=\alpha_{j}+\beta^{\prime} x_{i t j}
$$

This model relies on the assumption that the relationship between the response variable and the individual level variable is identical for all groups. As no group-level explanatory variables are present in the model, ANCOVA is not able to identify relevant characteristics of the macro context.

The multilevel model follows the random components approach, where both intercepts and coefficients may vary in a random way (Goldstein, 1995; Raudenbush \& Bryk, 2002 and Snijders \& Boskers, 1999). The random component version of Equation $(2 b)$ is given by:

$$
\operatorname{logit}\left(p_{i t j}\right)=\log \left\lfloor p_{i t j} /\left(1-p_{i t j}\right)\right\rfloor=\boldsymbol{\alpha}_{\mathbf{j}}+\beta_{\mathrm{j}}{ }^{\prime} x_{i t j}
$$


where the regression coefficients $\alpha_{\mathrm{j}}$ and $\beta_{\mathrm{j}}$ are both random variables following a multivariate normal distribution with associated variances and covariances. These variances and covariances are the extra parameters that are estimated in random components models. If the latter are significant, then we can say that context effects are present.

In this multilevel modelling framework we will consider basically three submodels: the empty model, the random intercept model and the random slope model. The empty or unconditional model does not take explanatory variables into account. We specify the model such that the logit transformed discrete-time hazards logit ( $\left.p_{i t i}\right)$ have a normal distribution:

$$
\operatorname{logit}\left(p_{i t j}\right)=\gamma_{0}+\boldsymbol{u}_{\boldsymbol{o j}}
$$

where $\gamma_{0}$ is the population average and $\boldsymbol{u}_{0 j}$ the random deviation from this average for group $j$. These deviations $u_{0 j}$ are assumed to be independent normally distributed random variables with mean zero and variance $\tau_{0}^{2}$.

When there are variables present that are potentially explicative for the observed outcomes, then they are incorporated as a linear function:

$$
\operatorname{logit}\left(p_{i t j}\right)=\gamma_{0}+\sum_{h=1}^{r} \gamma_{h} x_{h i t j}+\boldsymbol{u}_{o j}
$$

where $x_{h i t j}$ are level-one or level-two variables and $\gamma_{h}(h=1, \ldots, r)$ the slope parameters. Note that $r$ is the total number of covariates. We call (9) the random intercept model.

Now it cannot be excluded that the relation between the dependent variable and the explanatory variables can differ between groups. Therefore we extend the expression for the logit of the success probability with the random effects term $u_{j} x_{i j}$. This term accounts for the interaction between country $j$ and covariates $x_{h}$ :

$$
\operatorname{logit}\left(p_{i t j}\right)=\gamma_{0}+\sum_{h=1}^{r} \gamma_{h} x_{h i t j}+\sum_{h=1}^{r} \boldsymbol{u}_{h j} x_{h i t j}+\boldsymbol{u}_{\boldsymbol{o j}}
$$

Such a model implies that the countries are characterised by two types of random effects: random intercepts $\boldsymbol{u}_{0 \mathrm{j}}$ and random slopes $\boldsymbol{u}_{\boldsymbol{h}}$. Both effects have zero means. In most applications not all regression slope parameters will be considered as random, but just a subset of them. In our case, only the first variable (education) has a random slope $u_{1 j}$. Therefore $u_{2 j}=\ldots=u_{r j}=0$ for $j=1$ to 15 . In this case of an intercept and a single random slope, we have the intercept variance $\operatorname{var}\left(\boldsymbol{u}_{0 j}\right)=\tau_{0}{ }^{2}$, the 
slope variance var $\left(\boldsymbol{u}_{1 j}\right)=\tau_{1}^{2}$ and the intercept-slope covariance $\operatorname{cov}\left(\boldsymbol{u}_{0 j}, \boldsymbol{u}_{1 j}\right)=\tau_{01}$. If we would drop the random terms in (10) then we obtain a standard logistic regression model:

$$
\operatorname{logit}\left(p_{i t j}\right)=\gamma_{0}+\sum_{h=1}^{r} \gamma_{h} x_{h i t j}
$$

Such a model does not take any heterogeneity into account, but we will use it as a benchmark model in Section 5.

\subsection{Estimation Procedure}

How are multilevel discrete-time hazard models estimated in practice? We can simply use the equivalence between the log-likelihood of the discrete-time hazard analysis model and the logistic regression model discussed in Section 3.1. Therefore, estimating a multilevel discrete-time hazard model reduces to estimating a multilevel logistic regression model that belongs to the broader class of generalised linear mixed models (GLMM). Such a multilevel logistic regression model is specified in two stages.

First, conditional on the random effects $\boldsymbol{u}$, the data $y$ are assumed to follow a Bernoulli distribution $f(y \mid \boldsymbol{u} ; \beta)$. Second, the distribution of the random effects is assumed to be multivariate normal with mean zero and covariance matrix $\Sigma$. The likelihood function is now the marginal mass function of the observed data viewed as a function of the parameters

$$
L(\beta, \Sigma \mid y)=\int f(y \mid \boldsymbol{u} ; \beta) f(\boldsymbol{u} ; \Sigma) d u
$$

The above function needs to be maximised with respect to $\beta$ and $\Sigma$, but the likelihood function is extremely complex here. Most of the time intractable integrals, whose dimension depends on the structure of the random effects, are involved in (12) (Agresti et al., 2000). To tackle this problem, basically three different strategies have been implemented in practice: numerical integration, analytical approximation of the likelihood and Bayes method with diffuse priors. From the point of view of the quality of estimates, the numerical integration method is clearly superior to the other two. With this method the approximations converge to the ML estimates as they are applied more finely (e.g., by increasing the number of quadrature points in Gauss- 
Hermite quadrature methods). Also reliable likelihood ratio tests (LR-tests) can be performed. We will use LR-tests to test the nullity of specific parameters.

The estimation and testing has been carried out by the GENMOD procedure of the SAS-software package for the separate regressions models (5), the ANCOVA model (6) and the standard logistic regression model (11). The multilevel models (8), (9) and (10) have been analysed using the adaptive Gaussian quadrature method of SAS PROC NLMIXED. It was noticed that long computation times are required for large data sets. Therefore, by switching from person-months to person-years computing times are kept manageable. The resulting loss of precision in the estimates is usually minimal (Allison, 1995).

\section{$4 \quad$ Research Hypotheses}

In this study we test three different hypotheses:

Hypothesis 1 (individual level): Educated two-child mothers have a lower discretetime hazard rate of having a third child compared to uneducated two-child mothers.

Hypothesis 2 (country level): The Scandinavian society model has a positive effect on the discrete-time hazard rate of having a third child.

Hypothesis 3 (cross level interaction): Living in a Scandinavian country interacts with the effect of the mother's education on the discrete-time hazard rate of having a third child.

First, as a way of exploring the problem, we use two naive approaches to our multilevel problem. In section 5.1 we apply a non-hierarchical model: single-level discretetime hazard analysis and in section 5.2 we apply a varying intercepts model: analysis of covariance discrete-time hazard analysis. Finally, in Section 5.3 we apply the different multilevel models.

Let us recall the variables being used as covariates in the different models already discussed in Section 2. At the individual level, we have: 
- $e d u c_{i j}=$ the educational level of mother $i$ in country $j$, the covariate of primary theoretical interest. This is a categorical variable that can take on the values LOW, MED and HIGH. ${ }^{1}$

- labour $_{i j}=$ the labour force participation of the mother, a binary control variable

- cohort $_{i j}=$ year of birth of the mother, a control variable

- interbirth $_{i j}=$ the first interbirth interval, a control variable

- time $_{i t j}$ and timesq $_{i t j}=$ a quadratic representation for the baseline hazard

At the country level there is:

- Scandinavia ${ }_{j}$ indicates whether a woman lives in Scandinavia (Scandinavia =1) or not, a covariate of primary interest.

There is also one cross-level interaction:

- Scandinavia ${ }_{j} \mathrm{x}$ educ $\mathrm{i}_{\mathrm{ij}}$ : accounts for the heterogeneity across countries of the effect of education on third birth intensity.

\section{$5 \quad$ Results}

\subsection{Separate Regressions}

For each country separately, a discrete-time hazard model is estimated (Equation 5). We test for research hypothesis one and expect to find for education a strictly negative effect on third birth rates, as believed in conventional theory.

First, we briefly summarise the effect of the control variables (not reported in Table $2)$. For Austria $(p<.0001)$, Germany-E $(p=0.048)$, Germany-W $(p<.0001)$, Hungary $(p=0.033)$, Spain $(p<.0001)$ and Sweden $(p=0.008)$ significant cohort effects are found. Significant negative effects $(p<.0001)$ of First birth interval are found for all countries, as expected.

In Table 2, we show the estimated coefficients for education (corresponding to 2 dummy variables Educ-Low and Educ-Med, with Educ-High as reference category) and their $p$-values. Also the significance level for the Wald-test to decide if the effects of the low and medium category are different is presented.

${ }^{1}$ LOW corresponds to ISCED codes $0,1,2$ (education upto 3 years of secundary school), MED to
ISCED code 3 (secondary school completed), and HIGH to ISCED code 4-5-6 (Higher Education). 
(Table 2, about here)

We have found four (to five) different types of relationships between education and third births: no relationship, partly negative, partly positive and u-shaped. In Belgium, Germany-East, Latvia, Norway and Sweden, no significant effect of education on third birth rates seems to be present. In Italy and Spain, the low educated two-child mothers have higher third birth rates compared to the middle-educated group. More pronounced negative effects exist for Finland, France, Lithuania, Poland and Slovenia. Here, the low educated mothers have higher third birth rates, compared with both middle and highly educated mothers. However, the relationship is not strictly negative: there is no significant difference between the middle and highly educated group. For Austria and Germany-West we see a positive relationship. But again, this effect is not positive over the entire range: the low and the middle-educated group have comparable third birth levels. Still another, U-shaped pattern seems to prevail in Hungary. Here, compared with the middle-educated groups, both low and highly educated groups have higher third birth rates.

(Figure 1, about here)

We summarise the findings for the separate regressions analysis in Figure 1 in terms of odds-ratios. Out of fifteen, only seven countries show - as predicted by conventional theory- a negative relationship between education and third births. Other functional forms found are ranging from flat over U-shaped to partly positive. However, neither strictly negative nor strictly positive relationships are present. This variation between countries is not completely at random. We see a geographic pattern emerge. The positive effects-group consists of West-European countries only: Austria and Germany-West. The strongest negative effects are found among East-European countries: Lithuania, Poland and Slovenia.

\subsection{Analysis of Covariance}

In analysis of covariance (ANCOVA) the intercepts are allowed to vary in a nonrandom way (Equation 6). The assumption is that individual level effects (e.g., education) are the same for all higher level units, i.e. countries. Therefore, dummy variables for the countries are introduced. For the reference category (Sweden) no dummy is needed. In Table 3 we show the estimated coefficients for such an ANCOVA-type discrete-time hazard model. 
(Table 3, about here)

According to this model Finland, France, Norway and Sweden have essentially the same high levels of third birth rates. Belgium and Poland have slightly smaller third birth rates. The third birth rates for Austria, Germany-West, Italy, Latvia and Spain are moderate. Germany-East, Hungary, Lithuania and Slovenia have low levels of third birth rates (See Figure 2).

(Figure 2, about here)

The effect of education, now fixed by the model to be constant over countries, can be seen to be U-shaped: both lower and high-educated women have significantly higher third birth rates compared to middle-educated women. However, the results for separate regressions do not suppor the hypothesis of a constant relationshipbetween education and third birth rates across countries. To allow for country variation in the effect of education a way out within the context of ANCOVA is to use 44 country $\mathrm{x}$ education dummy variables with highly educated Swedes as the reference group. However, in terms of parsimonyof the model this is not an appropriate solution.

\subsection{Multilevel Analysis}

For modelling the country level random effects, we use the two-step approach advocated by Raudenbusch and Bryk (2002). In a first stage of model building, models with only individual level effects (Table 4) are estimated. Subsequently in a second stage, models with both individual level and country level effects including cross-level interactions are estimated (Table 5).

In Table 4, we compare four different models that have only individual level covariates included. Model 1 is a null or empty random model (Equation 8). Model 2 represents a logistic regression model (Equation 11). Model 3 is a random intercept model (Equation 9). Finally, Model 4 is a random slope model with a random effect for education only (Equation 10). The Models we are actually interested in are the 
multilevel models 3 and 4 . Models 1 and 2 are presented for reasonsof comparison only.

(Table 4, about here)

The regression coefficients for education in Models 2, 3 and 4 are univocal: education has a negative effect on the timing of third births. However, only the lower educated women have higher third birth rates compared to both middle and higher educated women. No significant difference is found between the middle and higher educated women. This result seems to confirm Hypothesis 1. What about the variances? Model 3 has only one variance component, i.e. for the intercept. Model 4 has three variance components: one variance term for the intercept, one variance term for education and one covariance term. The variances of the intercept in the random intercept model (Model 3) and the random education model (Model 4) are of the same magnitude: 0.113 and 0.132 respectively. The variance for education equals 0.037 . To test the null hypothesis that the random intercept variance equals zero, we use the Likelihood Ratio test and compare the logistic regression model (Model 2) with the random intercept model (Model 3). The difference in deviance between both models is large (323). The Likelihood Ratio test for introducing the random effect for education (by comparing Model 3 and Model 4) gives a difference of 11 deviance units. The size of this difference is rather moderate, but still significant. So there is substantial variance in the coefficient of education and even more variance in the random intercept. The latter could be explained by country-level covariates.

We introduce two such country-level variables in Models 5 and 6. In Model 5, we include the second-level variable Scandinavia in the multilevel model. This allows us to evaluate Hypothesis 2, whether Scandinavian societies are associated with a higher hazard of third births. Furthermore in Model 6, a cross-level effect Education $x$ Scandinavia is added. Hypothesis 3 is put to a test here. The results for both models are given in Table 5.

(Table 5, about here)

The coefficient for Scandinavia in Model 5 indicates that living in Scandinavia is associated with 0.446 higher log-odds of having a third birth. The difference in deviance between the models 4 en 5 is 5 units. Comparing to the $5 \%$ critical value 3.84 of 
a chi-squared distribution with one degree of freedom, yields a significant (although not highly significant) confirmation of Hypothesis 2.

Adding a cross-level interaction term for education and Scandinavia results in a non significant 3 point change in deviance. No support for hypothesis three is found. We did found empirical support for a weakend negative effect of eduction on third birth rate in Scandinavian countries. Finally, note that the estimates of the variances of the random effects are about the same in each of the two models. The intercept variance drops from 0.132 to 0.108 by introducing the country variable Scandinavia. No reduction is noticed for the slope variance when introducing the cross-level interaction term.

\section{Discussion}

In this paper, we have used FFS-data from fifteen European countries (Austria, Belgium, Germany-East, Germany-West, Finland, France, Hungary, Italy, Latvia, Lithuania, Norway, Poland, Slovenia, Spain and Sweden) to statistically assess the varying impact the education of the mother may have on third births across Europe. We have applied discrete-time hazard analysis in three different ways: single level analysis, conventional hierarchical analysis and modern multilevel analysis. In a first approach, we have analysed each country-based data set separately using exactly the same regression model. We found different types of functional relationships between education and third birth rates according to an intriguing geographical pattern. Could it be that merely coincidence, unobserved heterogeneity or design effects yielded these geographical preferences? Or, could it be that societal characteristics are behind?

In this paper we empirically verified this question by applying the modern random coefficient multilevel modelling framework to the pooled data set. From this analysis, we found that using the FFS-data human capital accumulation theory is not falsified: the effect of education is showed to be negative. As a proxy for societal characteristics the macro-level variable "Scandinvia" has been used. The effect of the Nordic model on third birth level is clearly present, but no significant cross-level interaction (between country and education) was found. 


\section{Acknowledgements}

This research was supported by a FWO grant Bijzondere doctoraatsbeurs 20022003. Part of this research was conducted at CBGS Brussels. We are grateful to many people from who we got interesting ideas and comments. Special thanks go to Prof. Robert Cliquet (former head of the CBGS, Brussels) as one of the founding fathers of the FFS survey, Prof. Jan Hoem (Max Planck Institute) for his inspiration on third birth analysis and the PAU (Geneva) for making available the FFS standard recode files. 


\section{References}

Adams, G. and R. Watson (1989), A Discrete-Time Parametric Model for the Analysis of Failure Time Data, Australian Journal of Statistics, 31, pp. 365-384.

Agresti, A., J. Booth, J. Hobert and B. Caffo, (2000), Random Effects Modelling of Categorical Response Data, In: Becker, M. (Ed.), Sociological Methodology 2000, Malden, MA: Blackwell Publishers Inc., pp. 27-80.

Allison, P.D. (1982), Discrete-Time Methods for the Analysis of Event Histories, In: Leinhardt, S. (Ed.), Sociological Methodology 1982, San Francisco: JossyeBass, pp. 61-98.

Allison, P.D. (1995), Survival Analysis Using the SAS System: A Practical Guide, Cary, NC: SAS Institute Inc.

Berinde, D. (1999), Pathways to a Third Child in Sweden, European Journal of Population, 15:4, pp. 349-378.

Bongaarts, J. and R. Potter (1983), Fertility, Biology and Behavior. An Analysis of the Proximate Determinants, New York: Academic Press.

Brown, C.C. (1975), On the Use of Indicator Variables for Studying the Time Dependence of Parameters in a Response-Time Model, Biometrics, 31, pp. 943947.

Callens, M. (1997), Arbeidsmarktparticipatie en het derde kind in Vlaanderen, Nego $\checkmark$ resultaten, Bevolking en Gezin, 2, pp. 97-119.

Corman, D. (2000), Family Policies, Working Life arrangements, and the Third Child in Two Low-Fertility Populations: a Comparative Study of Contemporary France and Sweden, Stockholm Research Reports in Demography, $\mathrm{n}^{\circ} 140$, Stockholm: Stockholm University.

Goldstein, H. (1995), Multilevel Statistical Models, London: Edward Arnold. 
Hobcraft J. and G. Rodriguez (1992), Methodological Issues in Life Table Analysis of Birth Histories. In: Allan G. Hill and William Brass (Eds.), The Analysis of Maternity Histories, IUSSP, Liège: Ordina, pp. 53-95.

Hoem, B. and J. Hoem (1989), The Impact of Women's Employment on Second and Third Births in Modern Sweden, Population Studies, 46, pp. 47-67.

Hoem, J.M., A. Prskawetz and G. Neyer (1999), Third Births in Austria: the Effect of Public Policies, Educational Attainment and Labor-Force Attachment, Working Paper 1999-02, Rostock: Max Planck Institute for Demographic Research.

Kasarda, J.D., Billy J.O.G and K. West (1986), Status Enhancement and Fertility. Reproductive Responses to Social Mobility and Educational Opportunity. Orlando: Academic Press.

Kravdal, Ö (1992), The Emergence of a Positive Relation Between Education and Third Birth Rates in Norway with Supportive Evidence from the United States, Population Studies, 46, pp. 459-475.

Kreft, I.G. and J. de Leeuw (1998), Introducing Multilevel Modelling, London: Sage Publications.

Myers, M. H., Hankey, B.F and N. Mantel (1973), A Logistic-Exponential Model for Use with Response-Time Data Involving Regressor Variables, Biometrics, 29, pp. 257-269.

Raudenbush, S.W. and A.S. Bryk (2002), Hierarchical Linear Models, Thousand Oaks: Sage Publications.

Snijders, T.A.B. and R.J. Boskers, (1999), Multilevel Analysis, An Introduction to Basic and Advanced Multilevel Modelling, London: Sage Publications. 
Table 1 Selected Characteristics of the Working Sample of Two-Child Mothers by Country

\begin{tabular}{lrrr}
\hline Country & Sample Size & Fieldwork & Year of Birth \\
\hline Austria & 1378 & 1995 to 1996 & 1941 to 1976 \\
Belgium & 1061 & 1991 to 1992 & 1951 to 1969 \\
Finland & 1620 & 1992 & 1938 to 1967 \\
France & 991 & 1989 to 1990 & 1944 to 1972 \\
Germany-E & 506 & 1992 & 1952 to 1970 \\
Germany-W & 435 & 1992 & 1952 to 1970 \\
Hungary & 1365 & 1992 to 1993 & 1952 to 1973 \\
Italy & 1492 & 1995 to 1996 & 1946 to 1973 \\
Latvia & 888 & 1995 & 1945 to 1975 \\
Lithuania & 826 & 1994 to 1995 & 1944 to 1974 \\
Norway & 1284 & 1988 to 1989 & 1945 to 1965 \\
Poland & 1796 & 1991 & 1935 to 1972 \\
Slovenia & 983 & 1994 to 1995 & 1949 to 1974 \\
Spain & 1398 & 1994 to 1995 & 1945 to 1976 \\
Sweden & 1199 & 1992 to 1993 & 1949 to 1969 \\
& & & \\
Total & 17222 & 1988 to 1996 & 1935 to 1976 \\
\hline
\end{tabular}


Table 2 Effect of Education on Third Birth Rates in Separate DiscreteTime Hazard Regressions

\begin{tabular}{|c|c|c|c|c|}
\hline \multirow[t]{2}{*}{ Model } & \multicolumn{3}{|c|}{ Separate Logistic Regression Analysis* } & \multirow{2}{*}{$\begin{array}{r}\text { Low-Med } \\
\text { Contrast }^{* *} \\
p \text {-Value }\end{array}$} \\
\hline & Parameter & Estimate & $p$-Value & \\
\hline \multirow[t]{2}{*}{ Austria } & Educ_Low & -0.417 & 0.009 & 0.894 \\
\hline & Educ_Med & -0.399 & 0.003 & \\
\hline \multirow{2}{*}{ Belgium } & Educ_Low & -0.216 & 0.129 & 0.806 \\
\hline & Educ_Med & -0.215 & 0.084 & \\
\hline \multirow[t]{2}{*}{ Finland } & Educ_Low & 0.392 & 0.003 & 0.000 \\
\hline & Educ_Med & -0.093 & 0.464 & \\
\hline \multirow[t]{2}{*}{ France } & Educ_Low & 0.304 & 0.037 & 0.000 \\
\hline & Educ_Med & -0.219 & 0.169 & \\
\hline \multirow[t]{2}{*}{ Germany-E } & Educ_Low & 0.363 & 0.266 & 0.256 \\
\hline & Educ_Med & 0.026 & 0.914 & \\
\hline \multirow[t]{2}{*}{ Germany-W } & Educ_Low & -0.524 & 0.069 & 0.119 \\
\hline & Educ_Med & -0.839 & 0.006 & \\
\hline \multirow[t]{2}{*}{ Hungary } & Educ_Low & 0.027 & 0.890 & 0.000 \\
\hline & Educ_Med & -0.675 & 0.002 & \\
\hline \multirow[t]{2}{*}{ Italy } & Educ_Low & 0.276 & 0.252 & 0.001 \\
\hline & Educ_Med & -0.153 & 0.555 & \\
\hline \multirow[t]{2}{*}{ Latvia } & Educ_Low & 0.415 & 0.146 & 0.204 \\
\hline & Educ_Med & 0.096 & 0.591 & \\
\hline \multirow[t]{2}{*}{ Lithuania } & Educ_Low & 0.632 & 0.056 & 0.045 \\
\hline & Educ_Med & -0.005 & 0.979 & \\
\hline \multirow[t]{2}{*}{ Norway } & Educ_Low & 0.182 & 0.191 & 0.338 \\
\hline & Educ_Med & 0.056 & 0.629 & \\
\hline \multirow[t]{2}{*}{ Poland } & Educ_Low & 0.628 & 0.000 & 0.000 \\
\hline & Educ_Med & 0.129 & 0.434 & \\
\hline \multirow[t]{2}{*}{ Slovenia } & Educ_Low & 0.785 & 0.000 & 0.005 \\
\hline & Educ_Med & 0.196 & 0.393 & \\
\hline \multirow[t]{2}{*}{ Spain } & Educ_Low & 0.308 & 0.109 & 0.021 \\
\hline & Educ_Med & -0.172 & 0.523 & \\
\hline \multirow[t]{2}{*}{ Sweden } & Educ_Low & 0.040 & 0.800 & 0.993 \\
\hline & Educ_Med & 0.039 & 0.742 & \\
\hline
\end{tabular}

Notes: * Reference Category for Education is Educ_High.

** Wald Test for the Significance of the Difference between Educ_Low and Educ_Med 
Table 3 Effect of Country and Education on Third Birth Rates in Analysis of Covariance Discrete-Time Hazard Regression

\begin{tabular}{lrr}
\hline & Estimate & $p$-Value \\
\hline Parameter & -0.500 & 0.000 \\
Austria & -0.295 & 0.021 \\
Felgium & -0.148 & 0.266 \\
France & 0.083 & 0.348 \\
Germany-E & -0.849 & 0.000 \\
Germany-W & -0.615 & 0.000 \\
Hungary & -0.862 & 0.000 \\
Italy & -0.618 & 0.000 \\
Latvia & -0.433 & 0.029 \\
Lithuania & -0.851 & 0.000 \\
Norway & -0.088 & 0.548 \\
Poland & -0.186 & 0.039 \\
Slovenia & -0.978 & 0.000 \\
Spain & -0.408 & 0.000 \\
Sweden & 0.000 & \\
& & 0.000 \\
Educ-Low & 0.297 & 0.002 \\
Educ-Med & -0.151 & \\
Educ-High & 0.000 & \\
\hline
\end{tabular}


Table 4

Results of Multilevel Discrete-Time Hazard Regression of Third Births using Individual Level Variables

\begin{tabular}{|c|c|c|c|c|}
\hline Results & $\begin{array}{c}\text { Model } 1 \\
\text { Null } \\
\text { Random }\end{array}$ & $\begin{array}{c}\text { Model } 2 \\
\text { Logistic } \\
\text { Regression }\end{array}$ & $\begin{array}{l}\text { Model } 3 \\
\text { Random } \\
\text { Intercept }\end{array}$ & $\begin{array}{c}\text { Model } 4 \\
\text { Random } \\
\text { Education }\end{array}$ \\
\hline \multicolumn{5}{|l|}{ Individ. Characteristics } \\
\hline Educ-Low & - & 0.264 & $\begin{array}{r}0.278 \\
* * * *\end{array}$ & 0.285 \\
\hline Educ-Med & - & -0.071 & -0.069 & -0.066 \\
\hline Educ-High & - & 0.000 & 0.000 & 0.000 \\
\hline Time & - & 0.082 & $\underset{* * * *}{0.097}$ & 0.097 \\
\hline Timesq & - & $\begin{array}{r}-0.031 \\
* * *\end{array}$ & $\begin{array}{r}-0.031 \\
* * *\end{array}$ & $\begin{array}{r}-0.031 \\
* * *\end{array}$ \\
\hline Interbirth & - & -0.031 & -0.031 & -0.031 \\
\hline Cohort & - & $\begin{array}{r}-0.019 \\
* * *\end{array}$ & $\begin{array}{r}-0.007 \\
*\end{array}$ & -0.007 \\
\hline Labour & - & $\begin{array}{r}-0.406 \\
* * \star\end{array}$ & -0.468 & -0.467 \\
\hline \multicolumn{5}{|l|}{ Estimated variances } \\
\hline $\operatorname{Var}($ Intercept) & 0.142 & - & 0.113 & 0.132 \\
\hline Var(Education) & - & - & - & 0.037 \\
\hline Covar(Interc., Educ.) & - & - & - & -0.029 \\
\hline $\begin{array}{l}\text { Goodness of fit } \\
\text { Deviance }\end{array}$ & 39351 & 37908 & 37585 & 37574 \\
\hline
\end{tabular}


Table 5 Results of Multilevel Discrete-Time Hazard Regression of Third Births using Individual Level and Country Level Variables

\begin{tabular}{|c|c|c|}
\hline Results & $\begin{array}{l}\text { Model } 5 \\
\text { Random Education } \\
\text { Country Effect }\end{array}$ & $\begin{array}{c}\text { Model } 6 \\
\text { Random Education } \\
\text { Cross-Level Effect }\end{array}$ \\
\hline Individ. Characteristics & & \\
\hline Educ-Low & $\begin{array}{r}0.288 \\
* *\end{array}$ & 0.292 \\
\hline Educ-Med & -0.066 & -0.096 \\
\hline Educ-High & 0.000 & 0.000 \\
\hline Time & 0.097 & $\underset{* 0.097}{0}$ \\
\hline Timesq & -0.031 & -0.031 \\
\hline Interbirth & -0.031 & -0.031 \\
\hline Cohort & 0.007 * & -0.007 * \\
\hline Labour & -0.471 & -0.470 \\
\hline $\begin{array}{l}\text { Country Characteristics } \\
\text { Scandinavia }\end{array}$ & 0.446 & 0.413 \\
\hline $\begin{array}{l}\text { Cross-level effect } \\
\text { Educ * Scandinavia }\end{array}$ & - & -0.012 \\
\hline $\begin{array}{l}\text { Estimated variances } \\
\text { Var (Intercept) }\end{array}$ & 0.108 & 0.111 \\
\hline $\operatorname{Var}($ Educ) & 0.037 & 0.037 \\
\hline Covar (Intercept, educ) & -0.036 & -0.038 \\
\hline $\begin{array}{l}\text { Goodness of fit } \\
\text { Deviance }\end{array}$ & 37569 & 37566 \\
\hline
\end{tabular}


Fig. 1 Functional Form of the Relationship between Education (on three levels: LOW, MED and HIGH) and Third Birth Rates. Odds ratios estimates from Separate Discrete-Time Hazard Regressions for 15 European Countries

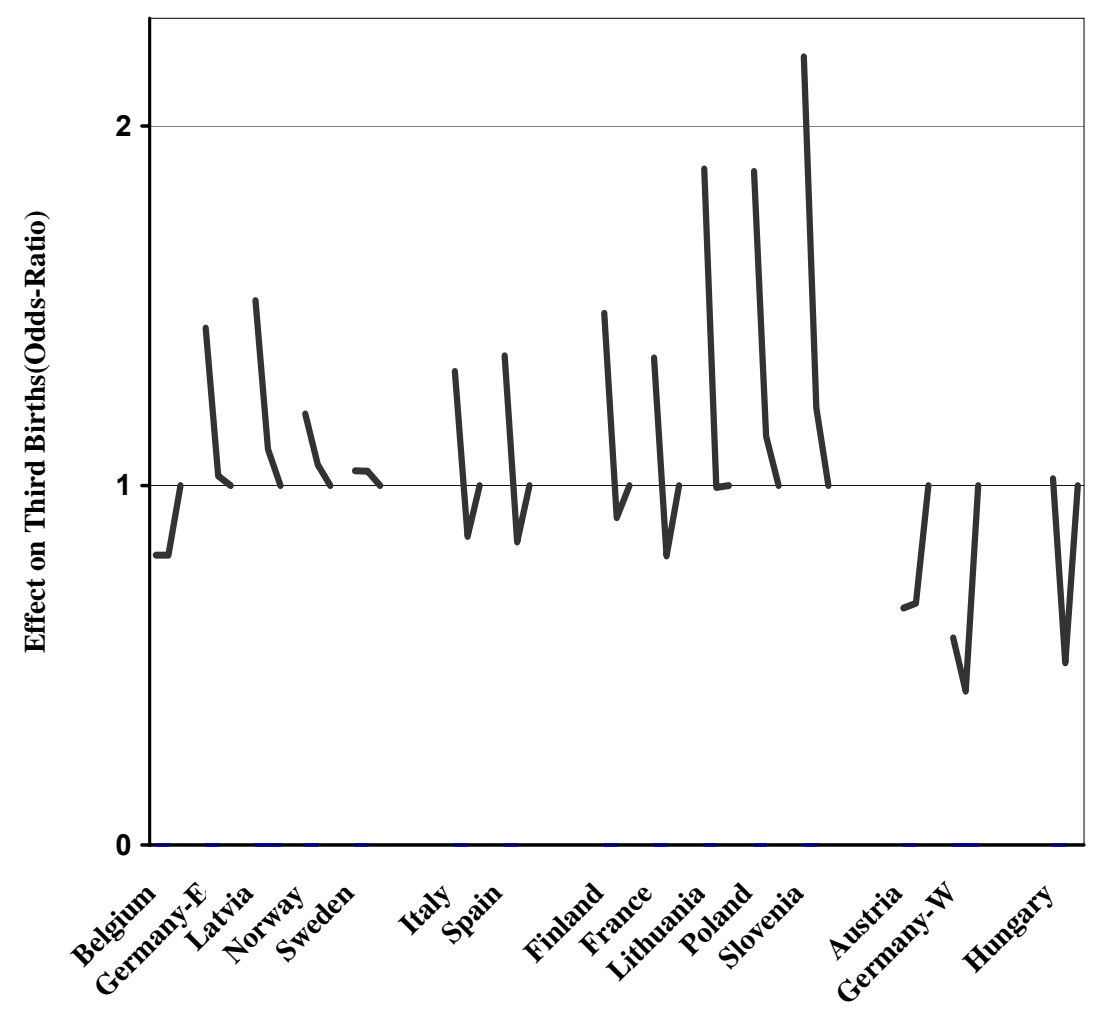

Country: Educ_Low, Educ_Med and Educ_high 
Fig. 2 Effect of Country on Third Birth Rates. Odds Ratios are estimated for Analysis of Covariance Discrete-Time Hazard Regression

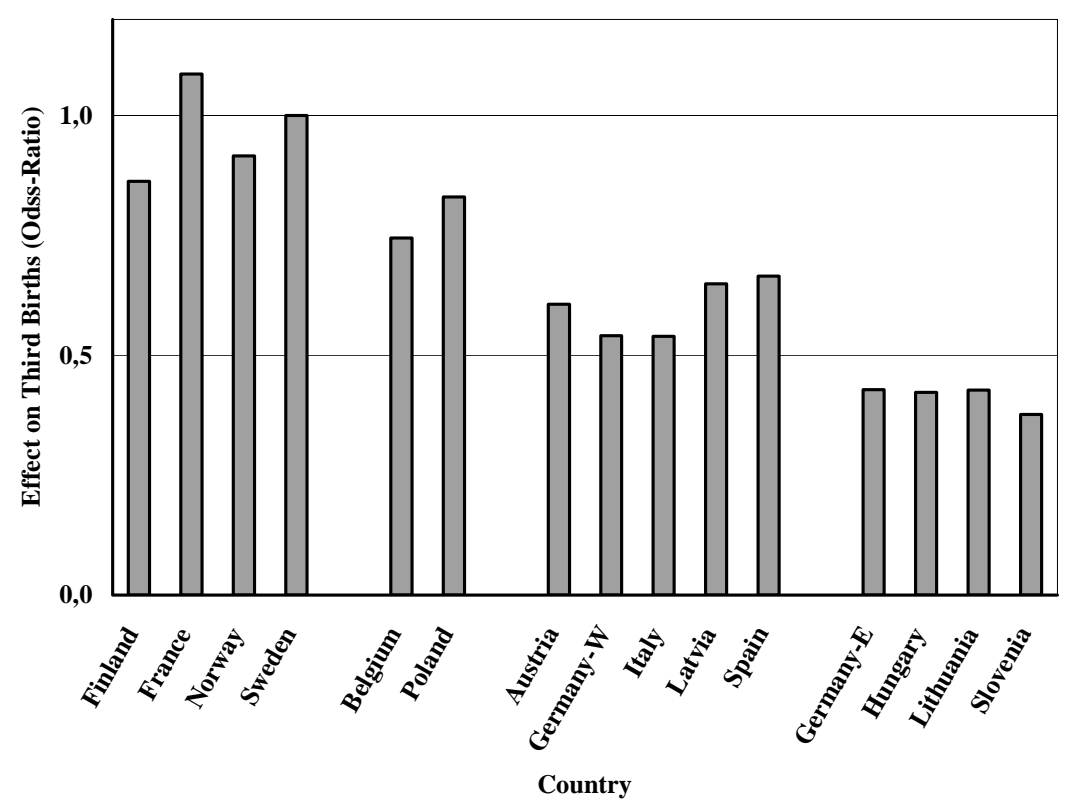

